\title{
Perencanaan Strategi Sistem Informasi Penanganan Tenaga Pendidik Terhadap Kualitas Peserta Didik di LPK. Duta Prima Prabumulih
}

\author{
Dahnial $^{1)}$ \\ ${ }^{1)}$ Program Studi Administrasi Negara STIA Satya Negara Palembang \\ Jl. Sukorejo Sukatani Kenten Telp.0711.826043 Palembang \\ Email :Dahnial_dp@yahoo.com ${ }^{1)}$
}

\begin{abstract}
The end result is the hope of the process that has been carried out, the strategy is a very basic tool to achieve the desired expectations. To realize the training and education institutions that have a commitment in achieving the vision and mission is a good end hope from the educators especially the expectations of each of the parents of the students by upholding discipline, which has not fully implemented and implemented the IS / IT, so information what is needed cannot be managed properly. For this reason, an ICT-based system is needed which is expected to be able to produce accurate and timely information. The purpose of this paper is to identify data and information needs in policy formulation and develop strategic information system plans. The basic concept used is the methodology proposed by John Ward and Peppard. The steps are carried out by analyzing the internal and external business environment of the Institute, internal and external IS / IT analysis of the institution, followed by the process of identifying the strategy, and designing future portfolios. The method of analysis was carried out using several analytical methods, among others, SWOT, Critical Success Factors, Value Chain, PEST, and Mc Farlan Strategic Grid.

The results of the research are the strategic planning blue print. The information produced will be integrated information for administrative needs and public services. Strategic objectives of IS / IT are excellent services that are reliable to be achieved with optimal implementation with ICT support. Preparation of IS / IT strategic planning according to the IS / IT portfolio produced so that it can have a positive impact on future strategic planning to obtain optimal results and based on contributions to the objectives to be achieved..
\end{abstract}

Keywords : Strategic Information System Planning, Ward \& Peppard Methodology

\section{Abstrak}

Hasil Akhir merupakan harapan dari proses yang telah dilaksanakan, strategi merupakan alat bantu yang sangat mendasar untuk mencapai harapan yang diinginkan. Untuk mewujutkan Lembaga pelatihan dan pendidikan yang memiliki komitmen dalam mewujutkan visi dan misi merupakan suatu harapan akhir baik dari Para tenaga pendidik terlebih lagi harapan dari masing masing orang tua para peserta didik dengan menegakkan disiplin, yang belum sepenuhnya menjalankan dan menerapkan SI/TI, sehingga informasi yang dibutuhkan belum dapat dikelola secara tepat. Untuk itu sangat diperlukan suatu sistem berbasis TIK yang diharapkan akan mampu menghasilkan informasi yang akurat dan tepat waktu. Tujuan dari penulisan ini adalah untuk mengidentifikasi kebutuhan data dan informasi dalam perumusan kebijakan dan mengembangkan rencana srategis sistem informasi. Konsep dasar yang digunakan adalah metodologi yang dikemukakan oleh John Ward dan Peppard. Tahapan yang dilakukan dengan melakukan analisa lingkungan bisnis internal dan eksternal Lembaga, analisa SI/TI internal dan eksternal lembaga, dilanjutkan dengan proses identifikasi strategi, dan melakukan rancangan portofolio masa yang akan datang. Metode analisis yang dilakukan menggunakan beberapa metode analisis antara lain, SWOT, Critical Success Factor, Value Chain, PEST, dan Mc Farlan Strategic Grid.

Hasil penelitian merupakan blue print perencanaan strategis. Informasi yang dihasilkan akan menjadi informasi yang terintegrasi untuk kebutuhan administratif dan pelayanan publik. Tujuan strategis SI/TI merupakan pelayanan prima yang handal untuk dapat dicapai dengan penerapan yang optimal dengan dukungan TIK. Penyusunan perencanaan strategis SI/TI sesuai portofolio SI/TI yang dihasilkan agar dapat memberikan dampak positif pada perencanaan strategis periode mendatang untuk memperoleh hasil yang optimal dan berdasarkan kontribusi pada tujuan yang akan dicapai.

Kata kunci : Perencanaan Strategis Sistem Informasi, Metodologi Ward \& Peppard 


\section{Pendahuluan}

Pada era Globalisasi saat ini Sistem informasi (SI) diharapkan dapat memberikan keunggulan kompetitif bagi lembaga LPK. Duta Prima yang merupakan senjata ampuh untuk meningkatkan efisiensi dan efektifitas dalam persaingan antar lembaga pendidikan, oleh karena itu hampir semua lembaga pendidikan ataupun organisasi pendidikan memanfaatkan teknologi informasi (TI). Jika kita melihat dari segi perencanaan, pengelolaan, dan implementasi maka dibutuhkan biaya yang tidak sedikit untuk menerapkan SI/TI sehingga perlu dilakukan perencanaan dan studi yang matang. Perencanaan strategis (Renstra) SI/TI merupakan langkah yang menyelaraskan dan mengembangkan juga dapat mendukung rencana dengan memperbaiki efisiensi kerja dengan membangun perencanan strategi berbagai proses yang mengelola informasi, meningkatkan manajemen dengan memuaskan kebutuhan informasi guna pengambilan keputusan. Selain itu juga dapat digunakan untuk memperbaiki daya saing serta meningkatkan keunggulan kompetitif lembaga dengan merubah gaya dan teknik bersaing dalam berbisnis.

Pada penelitian yang dilakukan, ruang lingkup penelitian dibatasi pada suatu bentuk usulan rencana startegi SI/TI di LPK. Duta Prima Prabumulih, dalam konteks penyediaan informasi yang akurat yang dapat dikembangkan guna mewujutkan hasil yang akan dicapai dalam penyelenggara pendidikan dan pelatihan dengan memberikan informasi yang akurat teknik Tenaga pendidik dalam penanganan peserta didik di bidang pendidikan untuk lebih memberikan peran penting dalam penanganan dan teknik pemberian materi kepada peserta didik secara konseptual dengan menggunakan metode Ward dan Peppard.

Penyusunan rencana strategis SI/TI merupakan suatu langkah menyelaraskan dan mengembangkan sistem dan teknologi informasi sesuai dengan strategi dan proses bisnis Penelitian ini merupakan penelitian deskriptif kualitatif menggunakan metodologi yang digunakan tidak lain untuk membangun perencanaan strategis sistem informasi di LPK. Duta prima adalah metodologi Ward dan Peppard. Pada tahapan analisis dengan mengacu pada kerangka kerja Perencanaan strategi Sistim Informasi SI/TI versi Ward dan Peppard, maka tahapan analisa pada penelitian ini dibagi menjadi empat tahap yaitu : Analisis kebutuhaan bisnis dan Informasi, Proses identifikasi target SI/TI, Proses identifikasi strategi SI/TI, dan Merancang portofolio mendatang.

\section{Pembahasan}

\section{A. Metode Penelitian}

1. Metode Pengumpulan data

Penelitian ini menggunakan metode pendekatan kualitatif, dengan melakukan penafsiran atau menginterprestasikan hasil berdasarkan data yang bersifat deskriptif yang diperoleh dari wawancara, observasi maupun studi literature. Sumber data yang digunakan berupa data primer dan data sekunder yang dilakukan selama \pm 3 bulan dari September 2017 sampai November 2017. Studi ini berisi sebuah yayasan yang telah memiliki rencana bisnis strategis berisi visi, misi dan tujuan. Untuk mempertahankan bisnis yang ada dan memiliki kemampuan untuk bersaing dengan lembaga lainnya, Lembaga membutuhkan perencananan strategis Sistem Informasi penangannan para Pendidik terhadap para peserta didik.

2. Tahapan Analisis dan Interpretasi Data

Pada tahapan analisis dengan mengacu pada kerangka kerja Perencanaan strategi Sistim Informasi SI/TI versi Ward dan Peppard, maka tahapan analisa pada penelitian ini dibagi menjadi empat tahapn yaitu : Analisis kebutuhaan bisnis dan Informasi, Proses identifikasi target SI/TI, Proses identifikasi strategi SI/TI, dan Merancang harapan portofolio mendatang.

\section{Analisis Lingkungan Bisnis Internal Lpk. Duta Prima}

Analisa lingkungan Bisnis Sistem Internal sebagai Analisa Pembanding Strategi Penanganan / Peserta didik/ Siswa di lembaga Lpk. Duta Prima Prabumulih dengan Lembaga pendidikan lain yang ada di kota prabumulih dapat dilihat pada gambar 1.0 dibawah ini, adalah analisa pembanding adalah sebagai berikut : Gambar 1. Strategi Tenaga Pendidik LPK. Duta Prima terhadap Peserta Didik

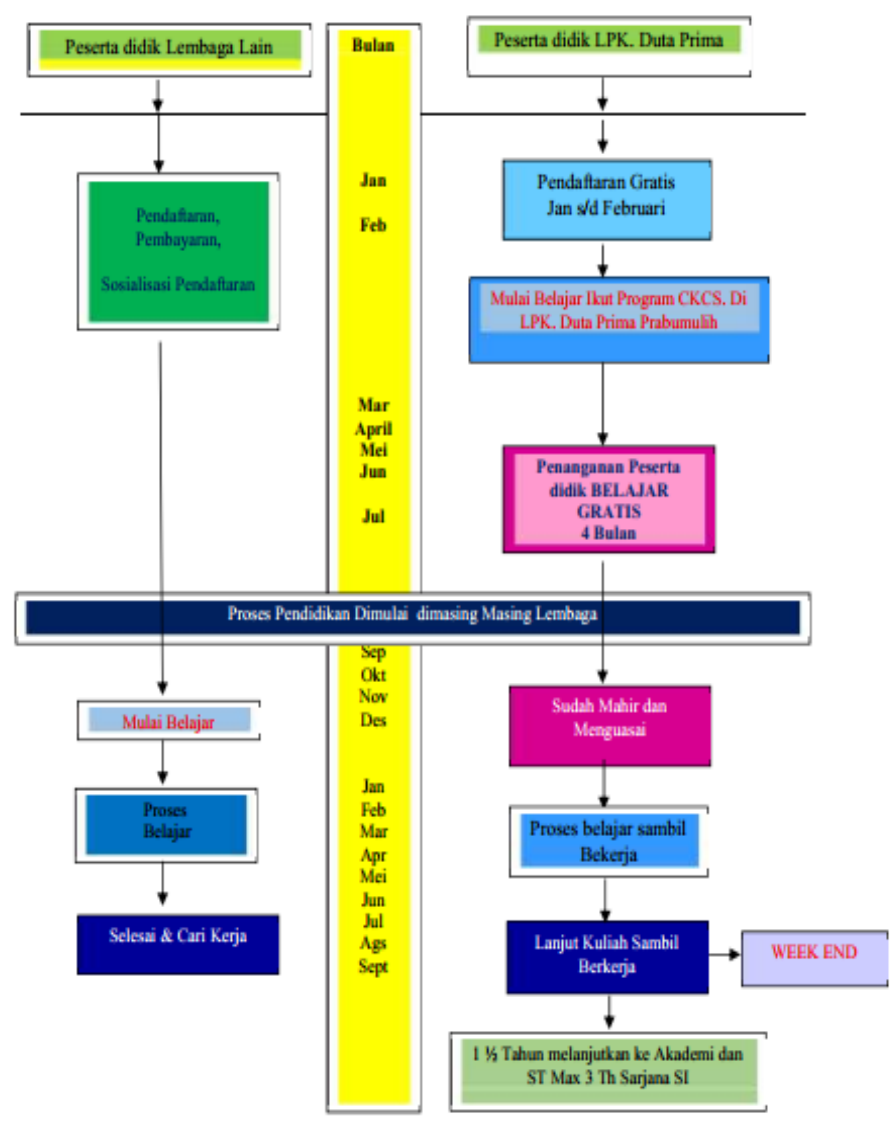

Gambar 1. Strategi Pembinaan dan Penanganan Peserta Didik / Siswa 
Tabel 1. Tujuan Utama dari Faktor keberhasilan Lembaga Lpk. Duta Prima Prabumulih.

\begin{tabular}{|c|c|c|c|}
\hline Perspektif & Strategi & $\begin{array}{l}\text { Ukuran } \\
\text { Kinerja }\end{array}$ & Target \\
\hline \multirow{5}{*}{$\begin{array}{l}\text { Calon } \\
\text { Profesional } \\
\text { Muda }\end{array}$} & $\begin{array}{l}\text { Sosialisa } \\
\text { si } \\
\text { Pendaftar } \\
\text { an }\end{array}$ & $\begin{array}{l}\text { Dapat } \\
\text { Terdaftar }\end{array}$ & $\begin{array}{l}\text { Membayar } \\
\text { uang } \\
\text { Pendaftara } \\
\text { n dan } \\
\text { Registrasi } \\
\text { selain } \\
\text { Program } \\
\text { Promo }\end{array}$ \\
\hline & $\begin{array}{l}\text { Penerima } \\
\text { an / } \\
\text { Promosi } \\
\text { dari } \\
\text { Bulan } \\
\text { Jan s/d } \\
\text { April }\end{array}$ & $\begin{array}{l}\text { Mengikuti } \\
\text { CKCS } \\
\text { Program } \\
\text { (Cepat Kerja } \\
\text { Cepat } \\
\text { Sarjana) }\end{array}$ & $\begin{array}{l}\text { Telah lebih } \\
\text { dahulu } \\
\text { memahami }\end{array}$ \\
\hline & $\begin{array}{l}\text { Pendaftar } \\
\text { an Gratis } \\
\text { pada } \\
\text { bulan } \\
\text { Januari } \\
\text { dan } \\
\text { Februari } \\
\text { Pendidik } \\
\text { an Gratis } \\
\text { pada } \\
\text { bulan } \\
\text { Maret s/d } \\
\text { Juli }\end{array}$ & $\begin{array}{l}\text { Belajar lebih } \\
\text { dahulu, lebih } \\
\text { dahulu } \\
\text { memahami }\end{array}$ & $\begin{array}{l}\text { Lebih } \\
\text { dahulu } \\
\text { Tau, } \\
\text { terlatih dan } \\
\text { Mahir dan } \\
\text { lebih } \\
\text { dahulu } \\
\text { memahami }\end{array}$ \\
\hline & $\begin{array}{l}\text { Bulan } \\
\text { Septemb } \\
\text { er Kelas } \\
\text { dimulai }\end{array}$ & $\begin{array}{l}\text { Sudah } \\
\text { menguasai } \\
\text { - terlatih } \\
\text { - Memahami } \\
\text { - Menguasai }\end{array}$ & $\begin{array}{l}\text { Menjadi } \\
\text { peserta } \\
\text { didik / } \\
\text { siswa yang } \\
\text { terlatih, } \\
\text { memahami } \\
\text {, dan } \\
\text { Menguasai } \\
\text { Materi }\end{array}$ \\
\hline & $\begin{array}{l}6 \text { bulan } \\
\text { ke depan } \\
\text { mencari } \\
\text { dan dapat } \\
\text { kerja }\end{array}$ & $\begin{array}{l}\text { Telah } \\
\text { menguasai, } \\
\text { Telah } \\
\text { terlatih } \\
\text { Lebih } \\
\text { percaya diri, } \\
\text { Harapan } \\
\text { mendapatka } \\
\text { n Salary }\end{array}$ & $\begin{array}{l}\text { Masih } \\
\text { mengikuti } \\
\text { proses } \\
\text { pendidikan } \\
\text { (Belum } \\
\text { selesai } \\
\text { mengikuti } \\
\text { pendidikan } \\
\text {, sudah } \\
\text { mendapat } \\
\text { Pekerjaan } \\
\text { dan } \\
\text { penghasila } \\
\text { n) }\end{array}$ \\
\hline
\end{tabular}

\begin{tabular}{|c|c|c|}
\hline $\begin{array}{l}\text { Proses } \\
\text { Pembelaj } \\
\text { aran } \\
\text { telah } \\
\text { selesai }\end{array}$ & $\begin{array}{l}\text { Sambil } \\
\text { berkerja } \\
\text { lanjut kuliah } \\
\text { WeekEnd } \\
\text { D3 -1 1/2 } \\
\text { Tahun } \\
\text { S1 } \pm 3 \\
\text { Tahun }\end{array}$ & $\begin{array}{l}\text { Melanjutka } \\
\text { n ke } \\
\text { jenjang } \\
\text { yang lebih } \\
\text { tinggi } \\
\text { dengan } \\
\text { waktu } \\
\text { yang } \\
\text { singkat, } \\
\text { Menjadi } \\
\text { Sarjana } \\
\text { lebih Cepat }\end{array}$ \\
\hline $\begin{array}{l}\text { Cepat } \\
\text { Berkerja }\end{array}$ & $\begin{array}{l}\text { Diminta oleh } \\
\text { Perusahaan } \\
\text { dengan } \\
\text { MOU }\end{array}$ & $\begin{array}{l}\text { Cepat kerja } \\
\text { Cepat } \\
\text { Sarjana } \\
\text { (CKCS } \\
\text { Program ) }\end{array}$ \\
\hline
\end{tabular}

\section{B. Hasil Analisa Rencana Strategis SI/TI}

Dari Sistem penanganan Strategi lembaga yang dilaksanakan diatas, maka diperlukan suatu strategi bagaimana penanganan peserta didik/siswa yang telah terdaftar langsung diberikan pendidikan gratis yang lebih awal. Peserta didik yang dididik dan dilatih selama kurang lebih empat bulan akan memberikan dampak yang sangat positif. Adapun manfaat yang didapat dari langkah strategi ini adalah :

Tabel 2. Hasil analisa strategi sistem pembinaan peserta didik / siswa

\begin{tabular}{|c|c|}
\hline Rencana Strategis & $\begin{array}{l}\text { Hasil yang akan } \\
\text { dicapai }\end{array}$ \\
\hline $\begin{array}{l}\text { - Penanganan peserta didik } \\
\text { lebih dini } \\
\text { - Peserta didik lebih } \\
\text { percaya diri untuk dapat } \\
\text { memahami materi } \\
\text { Pembelajaran } \\
\text { - Lebih mudah untuk } \\
\text { menyesuaikan diri kepada } \\
\text { lingkungan lembaga }\end{array}$ & $\begin{array}{l}\text { - Lebih mudah untuk } \\
\text { penyesuaian materi } \\
\text { pendidikan dan } \\
\text { pelatihan } \\
\text { - Sistem penanganan } \\
\text { peserta didik/siswa } \\
\text { dirasa lebih mudah } \\
\text { dan efisien } \\
\text { - Menyerapan materi } \\
\text { pembelajaran jauh } \\
\text { lebih mudah dalam } \\
\text { menyampaikan } \\
\text { materi } \\
\text { pembelajaran }\end{array}$ \\
\hline $\begin{array}{l}\text { - Dalam penguasaan materi } \\
\text { lebih dapat menguasai, } \\
\text { lebih terlatih dan } \\
\text { memahami }\end{array}$ & $\begin{array}{l}\text { Masih mengikuti } \\
\text { proses pendidikan } \\
\text { (Belum selesai } \\
\text { mengikuti } \\
\text { pendidikan,sudah } \\
\text { mendapat } \\
\text { Pekerjaan } \\
\end{array}$ \\
\hline $\begin{array}{l}\text { - Sambil berkerja lanjut } \\
\text { kuliah WeekEnd } \\
\text { - D3 - } 1 \frac{112 \text { Tahun }}{\text { - S1 } \pm 3 \text { Tahun }}\end{array}$ & $\begin{array}{l}\text { - Menjadi Sarjana } \\
\text { lebih Cepat }\end{array}$ \\
\hline $\begin{array}{l}\text { - Diminta oleh Perusahaan } \\
\text { dengan MOU }\end{array}$ & $\begin{array}{l}\text { - Cepat kerja Cepat } \\
\text { Sarjana (CKCS }\end{array}$ \\
\hline
\end{tabular}




\begin{tabular}{|l|l|}
\hline & Program ) \\
\hline • Harapan Alumni dapat & • Harapan menjadi \\
melanjutkan ke jenjang & Perguruan tinggi \\
yang lebih tinggi ke & baik Akademi \\
tingkat D3 dan S1 & maupun Sekolah \\
& tinggi komputer \\
& yang di harapkan \\
& oleh masyarakat \\
\hline
\end{tabular}

1. Analisis Critical Success Factor

\begin{tabular}{|c|c|c|}
\hline Tujuan & $\begin{array}{c}\text { Critical } \\
\text { Success Factor }\end{array}$ & $\begin{array}{c}\text { Prime } \\
\text { Meansure }\end{array}$ \\
\hline $\begin{array}{l}\text { Peningkatan } \\
\text { SDM }\end{array}$ & $\begin{array}{l}\text { Pemerataan dan } \\
\text { Peningkatan } \\
\text { SDM }\end{array}$ & $\begin{array}{l}\text { Peningkatan } \\
\text { ketersediaan } \\
\text { Tenaga } \\
\text { Pendidikan yang } \\
\text { Handal yang } \\
\text { bersertifikasi dan } \\
\text { berkualitas }\end{array}$ \\
\hline $\begin{array}{l}\text { Meningkatkan } \\
\text { Sarana dan } \\
\text { Prasarana } \\
\text { Pendidikan } \\
\text { dan Pelatihan }\end{array}$ & $\begin{array}{l}\text { Jumlah } \\
\text { tersedianya } \\
\text { Sarana dan } \\
\text { Prasarana } \\
\text { Pendidikan dan } \\
\text { Pelatihan } \\
\end{array}$ & $\begin{array}{l}\text { Penyediaan } \\
\text { sarana dan } \\
\text { prasarana } \\
\text { pendidikan dan } \\
\text { pelatihan }\end{array}$ \\
\hline $\begin{array}{l}\text { Meningkatkan } \\
\text { Kualitas } \\
\text { Manajemen } \\
\text { Pendidikan } \\
\text { dan Pelatihan }\end{array}$ & $\begin{array}{l}\text { Penguatan } \\
\text { Manajemen } \\
\text { satuan } \\
\text { pendidikan dan } \\
\text { Pelatihan }\end{array}$ & $\begin{array}{l}\text { Penguatan } \\
\text { Kualitas } \\
\text { Manajemen } \\
\text { Lembaga satuan } \\
\text { pendidikan dan } \\
\text { Pelatihan } \\
\end{array}$ \\
\hline
\end{tabular}

\section{Analisis SWOT}

Analisa SWOT dilakukan dengan mengidentifikasi kekuatan, kelemahan dan faktor-faktor positif dan faktor faktor negatif yang berasal dari internal lembaga serta peluang atau kesempatan dan keuntungan dari faktor eksternal dan ancaman atau resiko yang dipengaruhi oleh fakrtor eksternal lembaga.

Dengan mengetahui kekuatan yang dimiliki, lembaga dapat mempertahankan bahkan meningkatkan kekuatan sebagai modal untuk dapat terus bersaing dengan kompetitor lainnya. Mengidentifikasi kelemahan bertujuan untuk mengetahui kelemahan-kelemahan yang masih ada, dan dengan mengetahui kelemahan tersebut, maka lembaga akandapat berusaha untuk memperbaiki kelemahan yang ada agar menjadi lebih baik lagi. Berbagai strategi dapat disiapkan lebih dini dan terencana dengan lebih baik sehingga peluang yang telah diidentifikasi dapat terwujud. Banyak cara untuk dapat mewujudkan peluang dan mempertahankan kelangsungan lembaga pendidikan tentunya akan mengalami banyak ancaman yang dapat teridentifikasi untuk dapat dicarisolusi dari permasalahan yang dihadapi.

Analisis strategi ini digunakan sebagai dasar untuk merumuskan strategi pencapaian visi, misi dan tujuan lembaga. Dengan pemikiran yang tepat serta strategi yang terencana, diharapkan diperoleh rumusan strategi pencapaian tujuan yang tepat dan realistis untuk dilaksanakan. Empat kemungkinan alternatif strategis dihasilkan dari matriks SWOT.

Tabel 4. Matriks SWOT yang menghasilkan analisis strategi

(Sumber: Ward and Peppard, 2002)

\begin{tabular}{|c|c|c|}
\hline $\begin{array}{l}\text { Internal } \\
\text { Eksternal }\end{array}$ & $\begin{array}{l}\text { Kekuatan } \\
\text { (Strengths) }\end{array}$ & $\begin{array}{l}\text { Kelemahan } \\
\text { (Weaknesses) }\end{array}$ \\
\hline $\begin{array}{l}\text { Peluang } \\
\text { (Opportuni } \\
\text { ties) }\end{array}$ & $\begin{array}{l}\text { STRATEGIS - O } \\
\text { Ciptakan strategi } \\
\text { yang } \\
\text { menggunakan } \\
\text { kekuatan untuk } \\
\text { memanfaatkan } \\
\text { peluang }\end{array}$ & $\begin{array}{l}\text { STRATEGIW - O } \\
\text { Ciptakan strategi } \\
\text { yang } \\
\text { meminimalkan } \\
\text { kelemahan untuk } \\
\text { memanfaatkan } \\
\text { peluang }\end{array}$ \\
\hline $\begin{array}{l}\text { Ancaman } \\
\text { (Threats) }\end{array}$ & $\begin{array}{l}\text { STRATEGIS - T } \\
\text { Ciptakan strategi } \\
\text { yang } \\
\text { menggunakan } \\
\text { kekuatan untuk } \\
\text { mengatasi } \\
\text { ancaman }\end{array}$ & $\begin{array}{l}\text { STRATEGIW - T } \\
\text { Ciptakan stategi } \\
\text { yang } \\
\text { meminimalkan } \\
\text { kelemahan dan } \\
\text { menghindari } \\
\text { ancaman }\end{array}$ \\
\hline $\begin{array}{l}\text { Internal } \\
\text { Eksternal }\end{array}$ & $\begin{array}{l}\text { Kekuatan } \\
\text { (Strengths) }\end{array}$ & $\begin{array}{l}\text { Kelemahan } \\
\text { (Weaknesses) }\end{array}$ \\
\hline
\end{tabular}

Sebelum menentukan strategi SO, ST, WO, dan WT terlebih dahulu dilakukan scoring dengan menggunakan matrik IFAS dan EFAS.

Berikut adalah matrik Internal Strategic Factors Analysis Summary (IFAS) dapat dilihat pada tabel 4.3 dan matrik Eksternal Strategic Factors Analysis Summary (EFAS) dapat dilihat pada tabel 4.4 dimana bobot ditentukan dengan skala 0,0 (tidak penting) sampai 1,0 (sangat penting) berdasarkan kemungkinan dampak yang dihasilkan terhadap faktor strategis. Selanjutnya rating ditentukan dengan skala mulai 4 (outstanding) sampai 1 (poor) berdasarkan pengaruh faktor tersebut terhadap kondisi organisasi, penentuan rating untuk kelemahan dan ancaman dilakukan sebaliknya (Rangkuti 2003, p.24).

Tabel 5. Perhitungan EFAS LPK. Duta Prima Prabumulih

\begin{tabular}{|c|c|c|c|c|}
\hline \begin{tabular}{|c|} 
Faktor - \\
Faktor strategi \\
Eksternal \\
\end{tabular} & $\begin{array}{c}\text { Bob } \\
\text { ot }\end{array}$ & $\begin{array}{c}\text { Rati } \\
\text { ng }\end{array}$ & $\begin{array}{c}\text { Bobot } \\
\text { X } \\
\text { Rating }\end{array}$ & Komentar \\
\hline $\begin{array}{l}\text { PELUANG } \\
\text { (O) }\end{array}$ & & & & \\
\hline $\begin{array}{l}\text { 1. Dukungan } \\
\text { pemerintah } \\
\text { Kota } \\
\text { Prabumulih } \\
\text { dalam } \\
\text { melengkapi } \\
\text { sarana dan } \\
\text { prasarana }\end{array}$ & 0,10 & 3 & 0,30 & $\begin{array}{l}\text { LPK. Duta } \\
\text { Prima dapat } \\
\text { mengajukan } \\
\text { prososal ke } \\
\text { Pemerintah } \\
\text { Kota } \\
\text { Prabumulih } \\
\text { untuk } \\
\text { melengkapi } \\
\text { sarana dan } \\
\text { prasarana } \\
\text { Lembaga. }\end{array}$ \\
\hline
\end{tabular}




\begin{tabular}{|c|c|c|c|c|}
\hline $\begin{array}{l}\text { 2. Kesesuaian } \\
\text { sarana dan } \\
\text { prasarana } \\
\text { lembaga } \\
\text { dengan } \\
\text { tuntutan } \\
\text { potensi } \\
\text { daerah dan } \\
\text { per- } \\
\text { kembangan } \\
\text { IPTEK } \\
\text { serta } \\
\text { IMTAK }\end{array}$ & 0,10 & 4 & 0,40 & $\begin{array}{l}\text { Sarana dan } \\
\text { prasarana } \\
\text { merupakan } \\
\text { kekuatan yang } \\
\text { mendasar untuk } \\
\text { pemanfaatan } \\
\text { yang harus ada } \\
\text { di lembaga dan } \\
\text { harus } \\
\text { perbaharui. }\end{array}$ \\
\hline $\begin{array}{l}\text { 3. Tuntutan } \\
\text { masyarakat } \\
\text { terhadap } \\
\text { kualitas } \\
\text { lulusan } \\
\text { yang } \\
\text { berkualitas }\end{array}$ & 0,15 & 3 & 0,65 & $\begin{array}{l}\text { Masyarakat } \\
\text { mengharapkan } \\
\text { setelah selasai } \\
\text { mengikuti } \\
\text { pendidikan dan } \\
\text { pelatihan } \\
\text { diharapkan agar } \\
\text { cepat kerja dan } \\
\text { cepat sarjana, } \\
\text { artinya } \\
\text { dapat melanjutk } \\
\text { an kejenjang } \\
\text { yang lebih } \\
\text { tinggi dan } \\
\text { berkualitas }\end{array}$ \\
\hline $\begin{array}{l}\text { 4. Sponsor/ } \\
\text { perusahaan/ } \\
\text { yayasan }\end{array}$ & 0,10 & 3 & 0,30 & $\begin{array}{l}\text { Bantuan } \\
\text { sponsor guna } \\
\text { pengembangan } \\
\text { Lembaga } \\
\text { Pendidikan. } \\
\end{array}$ \\
\hline $\begin{array}{l}\text { 5. Harapan } \\
\text { dan } \\
\text { dukungan } \\
\text { orang tua } \\
\text { tinggi }\end{array}$ & 0,10 & 3 & 0,30 & $\begin{array}{l}\text { Terbukti hasil } \\
\text { alumni yang } \\
\text { telah selesai } \\
\text { telah dapat dan } \\
\text { cepat bekerja, } \\
\text { orang tua } \\
\text { yang mendaftar } \\
\text { kan } \\
\text { anaknya untuk } \\
\text { dapat dididik } \\
\text { agar dapat } \\
\text { berhasil seperti } \\
\text { kakak } \\
\text { tingkatnya. }\end{array}$ \\
\hline
\end{tabular}

\begin{tabular}{|c|c|c|c|l|}
$\begin{array}{l}\text { 2. Lingkungan } \\
\text { sosial } \\
\text { lembaga }\end{array}$ & 0,10 & 3 & 0,30 & $\begin{array}{l}\text { Keterbatasan } \\
\text { Pembagian } \\
\text { waktu } \\
\text { diperuntukkan } \\
\text { untuk para } \\
\text { peserta didik } \\
\text { untuk bebas } \\
\text { berlatih } \\
\text { mempermahir } \\
\text { dan berlatih }\end{array}$ \\
\hline $\begin{array}{l}\text { 3. Pusat } \\
\text { Berbagai } \\
\text { kegiatan }\end{array}$ & 0,05 & 3 & 0,15 & $\begin{array}{l}\text { Belum banyak } \\
\text { kegiatan yang } \\
\text { dipusatkan di } \\
\text { lembaga }\end{array}$ \\
\hline $\begin{array}{l}\text { 4. Persaingan } \\
\text { bisnis } \\
\text { pendidikan }\end{array}$ & 0,10 & 3 & 0,30 & $\begin{array}{l}\text { Banyak } \\
\text { Persaingan } \\
\text { bisnis lembaga } \\
\text { pendidikan lain } \\
\text { yang saling } \\
\text { berkompetisi }\end{array}$ \\
\hline $\begin{array}{l}\text { Teknologi } \\
\text { Komputer } \\
\text { dan }\end{array}$ & 0,10 & 3 & 0,35 & $\begin{array}{l}\text { Belum } \\
\text { seluruhnya } \\
\text { fasilitas } \\
\text { Informatika } \\
\text { sarana } \\
\text { pelatihan yang } \\
\text { diperbaharui. }\end{array}$ \\
\hline $\begin{array}{l}\text { JUMLAH } \\
\text { OT T }\end{array}$ & 1,00 & & 3,35 & \\
\hline
\end{tabular}

\section{Kesimpulan:}

Dapat dilihat dari butir peluang harapan masyarakat terhadap hasil para peserta didik yang dididik dan dilatih merupakan peluang yang paling besar yang dimiliki oleh LPK.Duta Prima untuk membuktikan kepada masyarakat, walaupun peluang ini masih harus lebih dimaksimalkan, Ancaman ini dapat diminimalisir dengan peluang tersebut dengan cara tidak hanya infrastruktur saja yang di pehatikan tapi tenaga pendidik jauh lebih diprioritaskan untuk dapat merealisasikan harapan lembaga kemasa mendatang.

Tabel 6. Perhitungan LPK. Duta Prima Praumulih

\begin{tabular}{|c|c|c|c|c|}
\hline \begin{tabular}{|c|} 
Faktor - \\
Faktor strategi \\
Internal
\end{tabular} & $\begin{array}{c}\text { Bobo } \\
t\end{array}$ & $\begin{array}{c}\text { Ratin } \\
\mathrm{g}\end{array}$ & $\begin{array}{c}\text { Bobot X } \\
\text { Rating }\end{array}$ & Komentar \\
\hline $\begin{array}{l}\text { KEKUATAN } \\
\text { (S) } \\
\text { 1. Motivasi } \\
\text { Pengajar } \\
\text { dan Peserta } \\
\text { didik }\end{array}$ & 0,15 & 3 & 0,45 & $\begin{array}{l}\text { Motivasinya } \\
\text { tinggi dengan } \\
\text { mampu } \\
\text { mengembangka } \\
\mathrm{n} \text { metode } \\
\text { pembelajaran } \\
\text { dan teknik } \\
\text { penanganan } \\
\text { peserta } \\
\text { didik cukup ant } \\
\text { usias dalam } \\
\text { mengikuti } \\
\text { program } \\
\text { pembekalan } \\
\text { gratis sebelum } \\
\text { proses belajar di }\end{array}$ \\
\hline
\end{tabular}




\begin{tabular}{|c|c|c|c|c|}
\hline & & & & mulai. \\
\hline $\begin{array}{l}\text { 2. Fasilitas } \\
\text { Ruang Lab. } \\
\text { Komputer } \\
\text { dan } \\
\text { perpustakaa } \\
\text { n. }\end{array}$ & 0,15 & 3 & 0,45 & $\begin{array}{l}\text { Selain kondusif, } \\
\text { kelengkapan } \\
\text { buku, soal } \\
\text { latihan dan alat } \\
\text { praktik yang } \\
\text { dimanfaatkan } \\
\text { peserta didik } \\
\text { tersedia dengan } \\
\text { cukup baik. }\end{array}$ \\
\hline $\begin{array}{l}\text { 3. Hubungan } \\
\text { yang baik } \\
\text { antara } \\
\text { Tenaga } \\
\text { Pendidik } \\
\text { dengan } \\
\text { peserta } \\
\text { didik sangat } \\
\text { baik. }\end{array}$ & 0,10 & 3 & 0,30 & $\begin{array}{l}\text { Sangat kondusif } \\
\text { baik dalam } \\
\text { kegiatan proses } \\
\text { belajar } \\
\text { mengajar } \\
\text { ataupun } \\
\text { pembelajaran } \\
\text { tambahan untuk } \\
\text { pembahasan } \\
\text { tugas. }\end{array}$ \\
\hline $\begin{array}{l}\text { 4. Pendekatan } \\
\text { dan Teknik } \\
\text { Pembahasa } \\
\text { n dan } \\
\text { pemberian } \\
\text { materi serta } \\
\text { metode } \\
\text { mengajar } \\
\text { yang } \\
\text { bervariasi }\end{array}$ & 0,10 & 3 & 0,30 & $\begin{array}{l}\text { Tenaga } \\
\text { pendidik } \\
\text { menggunakan } \\
\text { pendekatan, } \\
\text { metode } \\
\text { pembelajaran } \\
\text { yang bervariasi }\end{array}$ \\
\hline 5. Pembiyaan & 0,10 & 3 & 0,30 & $\begin{array}{l}\text { Orang tua } \\
\text { peserta didik } \\
\text { memiliki } \\
\text { kemampuan } \\
\text { membayar biaya } \\
\text { yang relatif } \\
\text { murah dan } \\
\text { terjangkau. }\end{array}$ \\
\hline $\begin{array}{l}\text { KELEMAAN } \\
\text { (W) } \\
\text { 1. Rekrutmen } \\
\text { Tenaga } \\
\text { Pendidik } \\
\text { dan staff }\end{array}$ & 0,15 & 3 & 0,45 & $\begin{array}{l}\text { Rekrutmen } \\
\text { Tenaga } \\
\text { Pendidik dan } \\
\text { staff } \\
\text { yang terkadang t } \\
\text { idak sesuai } \\
\text { dengan } \\
\text { kebutuhan dan } \\
\text { sarat } \\
\text { dengan unsur } \\
\text { kekeluargaan }\end{array}$ \\
\hline $\begin{array}{l}\text { 2. Keadaan } \\
\text { Tenaga } \\
\text { Pendidik }\end{array}$ & 0,10 & 3 & 0,30 & $\begin{array}{l}\text { Sebagian besar } \\
\text { tenaga } \\
\text { pendidik masih } \\
\text { berstatus } \\
\text { Honorer } \\
\text { dan mengajar } \\
\text { ditempat lain }\end{array}$ \\
\hline $\begin{array}{l}\text { 3. Penerimaan } \\
\text { peserta } \\
\text { didik } \\
\text { baru/pindah } \\
\text { an }\end{array}$ & 0,10 & 3 & 0,30 & $\begin{array}{l}\text { Peneriman } \\
\text { peserta didik } \\
\text { lulusan min sma } \\
\text { sederajat. }\end{array}$ \\
\hline 4. Jamsostek & 0,10 & 3 & 0,30 & $\begin{array}{l}\text { Adanya asurasi } \\
\text { bagi para } \\
\text { peserta didik }\end{array}$ \\
\hline
\end{tabular}

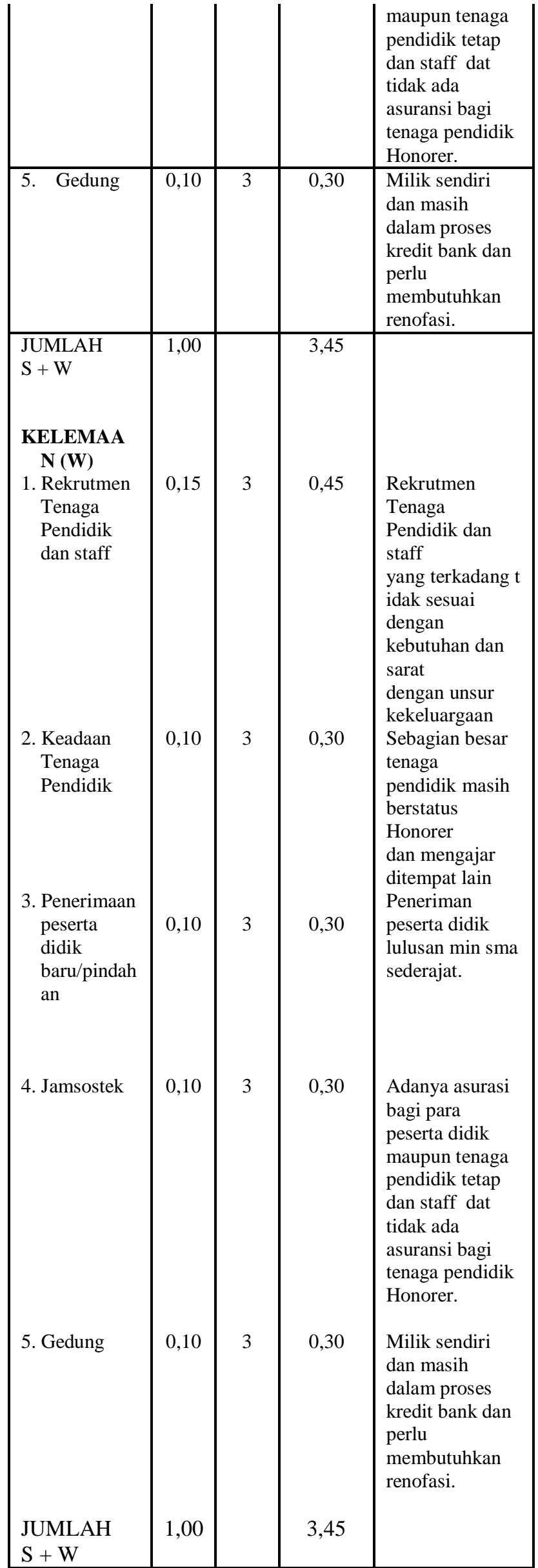


Dilihat dari bobot masing - masing butir Kekuatan dan kelemahan yang ada pada matrik diatas dapat disimpulkan bahwa antara kekuatan dan kelemahan yang dimiliki oleh LPK. Duta Prima Prabumulih ini seimbang baik dari skor dan rating. Hal ini bisa dijadikan pelajaran untuk pihak lembaga bahwa kekuatan yang ada kurang begitu dimaksimalkan untuk meminimalisir kelemahan yang ada. Diharapkan dengan analisis ini lembaga akan terus berusaha dan meningkatkan kekuatan lembaga LPK. Duta Prima dengan seoptimal mungkin agar kelemahan yang ada dapat teratasi.

Jumlah scoring yang didapatkan dari matriks Internal Strategic Factors Analysis Summary (IFAS) dan matrik External Strategic Factors Analysis Summary (EFAS) ditunjukkan pada Tabel 2.

Tabel 7. Matriks Internal - Eksternal

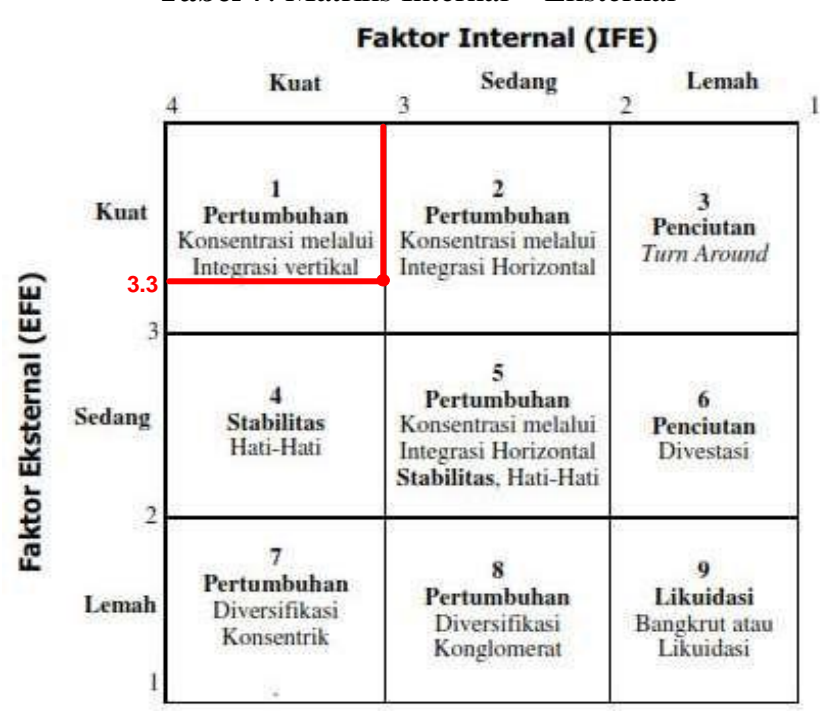

\section{Analisis Value Chain}

Analisis Value Chain merupakan suatu metode untuk merinci suatu rangkaian dari proses pendaftaran hingga menjadi tenaga siap kerja yang digunakan, menjadi kegiatan strategi yang relevan untuk memahami perilaku biaya dan perbedaan sumber daya. Analisis Value Chain terhadap lembaga LPK. Duta Prima Prabumulih.

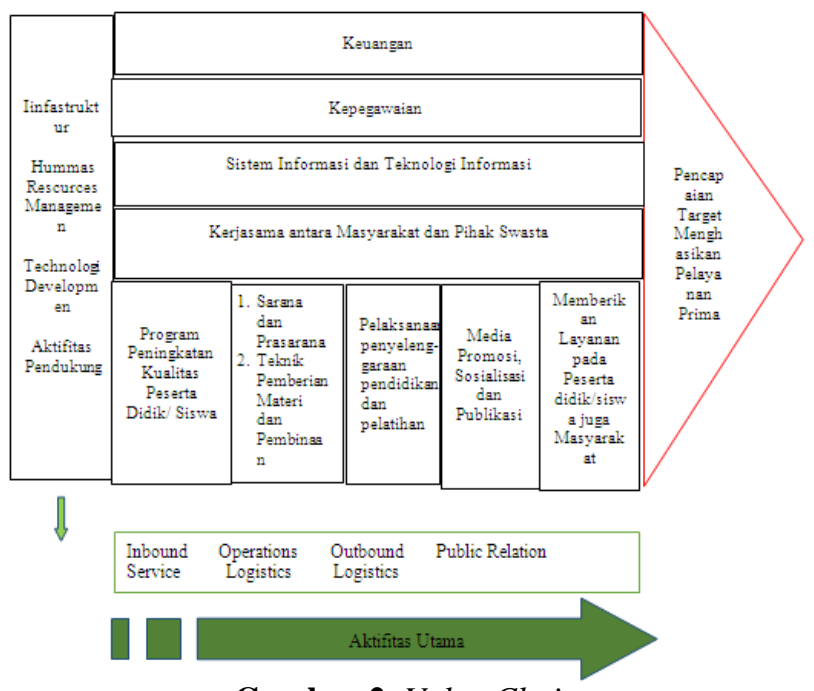

Gambar 2. Value Chain
4. Analisis PEST

Tabel 8. Analisis PEST

\begin{tabular}{|c|c|c|c|}
\hline Faktor & $\begin{array}{c}\text { Ancaman / } \\
\text { Peluang }\end{array}$ & Inisiatif & $\begin{array}{c}\text { Kebutuhan } \\
\text { SI / TI }\end{array}$ \\
\hline Politik & $\begin{array}{l}\text { Kebijakan } \\
\text { Anggaran } \\
\text { Pendidikan } \\
\text { Sebesar } \\
30 \%\end{array}$ & $\begin{array}{l}\text { Menmpertimban } \\
\text { gkan kebijakan } \\
\text { dan perubahan } \\
\text { anggaran yang } \\
\text { disesuaikan } \\
\text { dengan PAD } \\
\text { lembaga LKP. } \\
\text { Duta Prima } \\
\text { Prabumulih }\end{array}$ & $\begin{array}{l}\text { SI RAPLPK } \\
\text { ( Sudah ada) }\end{array}$ \\
\hline Ekonomi & $\begin{array}{l}\text { Peningkatan } \\
\text { pendapatan } \\
\text { Masyarakat }\end{array}$ & $\begin{array}{l}\text { Meningkatkan } \\
\text { publikasi } \\
\text { keunggulan } \\
\text { pendidikan di } \\
\text { kota Prabumulih }\end{array}$ & $\begin{array}{l}\text { Website } \\
\text { LPK. Duta } \\
\text { Prima } \\
\text { Prabumulih }\end{array}$ \\
\hline Sosial & $\begin{array}{l}\text { Pendapatan } \\
\text { masyarakat } \\
\text { dari sektor } \\
\text { perkebunan } \\
\text { mempengar } \\
\text { uhi minat } \\
\text { calon } \\
\text { peserta } \\
\text { didik untuk } \\
\text { mendaftar }\end{array}$ & $\begin{array}{l}\text { Memberikan } \\
\text { sosialisasi } \\
\text { keringanan dan } \\
\text { solusi } \\
\text { pembayaran }\end{array}$ & - \\
\hline Teknologi & $\begin{array}{l}\text { Pemanfaata } \\
\text { n Teknologi }\end{array}$ & $\begin{array}{l}\text { Pelatihan } \\
\text { pemanfaatan } \\
\text { TIK }\end{array}$ & $\begin{array}{l}\text { LMS ( } \\
\text { Learning } \\
\text { Managemen } \\
\text { System) } \\
\end{array}$ \\
\hline
\end{tabular}

5. Mc Farlan Strategic Grid

Tabel 9. Current Portfolio Application

\begin{tabular}{|l|l|}
\hline \multicolumn{1}{|c|}{ Strategy } & Hight Potensial \\
\hline Kunci Operasional & Support \\
\hline RAPBL (Rencana & - SI Penerimaan Peserta \\
Anggaran Pendapatan dan & Didik yang Baru \\
Belanja Lembaga) & • Web Disdik Kota \\
& Prabumulih \\
& - Aplikasi Penerimaan \\
& dan Pengembangan \\
& Pesertadidik. \\
\hline
\end{tabular}

6. Analisis Kebutuhan Informasi

Berdasarkan analisis kesenjangan (gap) yang telah dilakukan, maka selanjutnya perlu dilakukan kegiatan analisis kebutuhan informasi. Analisis kebutuhan informasi disini digunakan untuk mengidentifikasi apa yang menjadi critical success factor (CSF). Dan dari setiap CSF dilakukan pemetaan dengan menggunakan hasil yang didapat dari analisis SWOT, untuk menyelaraskan identifikasi yang didapat dari CSF dengan identifikasi yang didapat dari SWOT, untuk mendapatkan informasi mengenai kebutuhan akan informasi. 
Tabel 10. Analisis Kebutuhan Informasi

\begin{tabular}{|l|l|}
\hline \multicolumn{1}{|c|}{ Tujuan } & Kebutuhan Informasi \\
\hline $\begin{array}{l}\text { Peningkatan dan } \\
\text { Pemerataan Sumberdaya } \\
\text { Manusia }\end{array}$ & $\begin{array}{l}\text { Informasi Sumberdaya } \\
\text { Manusia yang } \\
\text { kompeten }\end{array}$ \\
\hline $\begin{array}{l}\text { Peningkatan Kualitas } \\
\text { Sarana dan Prasarana } \\
\text { Pendidikan }\end{array}$ & $\begin{array}{l}\text { Informasi dan Profile } \\
\text { Lembaga LPK. Duta } \\
\text { Prima Praumulih dan } \\
\text { asset Lembaga }\end{array}$ \\
\hline $\begin{array}{l}\text { Kualitas Manajemen } \\
\text { Pendidikan }\end{array}$ & $\begin{array}{l}\text { Informasi data Peserta } \\
\text { didik / siswa dan } \\
\text { akademik }\end{array}$ \\
\hline
\end{tabular}

7. Landasan Kebijakan SI/TI

Penentuan landasan kebijakan SI/TI didasarkan pada tujuan utama Lembaga yang dijabarkan sebagai tujuan dari CSF sehingga strategi SI/TI di lembaga LPK. Duta Pima Prabumulih merupakan strategi-strategi SI/TI yang mendukung Lembaga untuk :

1. Pengembangan aplikasi TIK untuk Pemerataan dan Peningkatan Sumber daya Manusia di lembaga.

2. Pengembangan aplikasi TIK Mendorong Peningkatan Kualitas Sarana dan Prasarana Pendidikan Lembaga.

3. Pengembangan aplikasi TIK peningkatan kualitas manajemen pendidikan dan pelatihan.

8. Strategi SI/TI

a. Strategi Bisnis SI/TI

1. Visi SI/TI

Menjadikan SI/TI sebagai strategi dalam mewujudkan Lembaga Pendidikan yang berkualitas, berwawasan global, berbudaya dan berakhlak mulia.

2. Misi SI/TI

a) Penyediaan SI/TI yang dapat meningkatkan pemerataan dan peningkatan Sumber daya Manusia

b) Penyediaan SI/TI yang dapat meningkatkan kualitas sarana dan Prsarana pendidikan dan pelatihan;

c) Penyediaan SI/TI yang dapat meningkatkan kualitas manajemen pendidikan.

3. Tujuan SI/TI

a) Tersedianya informasi yang lebih baik dalam upaya pemerataan dan peningkatan Sumber daya Manusia dengan terwujudnya peran TIK yang optimal dalam rangka peningkatan kualitas sarana dan prasarana pendidikan.

b) Terwujudnya peningkatan kualiatas manajemen pendidikan dan pelatihan berbasis TIK.

4. Sasaran Strategis SI/TI

a) Pembuatan pedoman pengembangan SI/TI;

b) Pembentukan divisi SI/IT;

c) Sistem Pengumpulan data pendidikan dan pelatihan;

d) sistem yang memudahkan analisa data pendidikan;

e) Sistem pembelajaran online.

b. Strategi Manajemen SI/TI

1. Pembuatan pedoman pengembangan SI/TI;

2. Pembentukan Divisi SI/TI;
3. Pembuatan Job Description Divisi SI/TI;

4. Peningkatan

5. anggaran pengembangan SI/TI.

c. Strategi SI/TI

1. Peningkatkan fungsi pengolahan data SDM yang optimal dengan dukungan TIK

2. Peningkatan peranan TIK secara optimal untuk penyediaan sarana dan prasarana pendidikan dan pelatihan yang berkualitas.

3. Pengembangan aplikasi TIK bagi peningkatan kualitas manajemen pendidikan dan pelatihan.

9. Portofolio Mendatang

a. Future Portfolio Application

Tabel 11. Portofolio aplikasi mendatang STRATEGIC $\quad$ HIGH POTENSIAL

\begin{tabular}{|l|l|}
\hline & \multicolumn{1}{|c|}{$\begin{array}{l}\text { Sasaran Kerja Karyawan (dalam } \\
\text { pengembangan) }\end{array}$} \\
\hline KEY & SUPPORT \\
\hline & $\begin{array}{l}\text { SI Penerimaan Peserta Didik } \\
\text { Baru (PPDB) } \\
\text { Web Disdik Kota Prabumulih } \\
\text { Aplikasi Office Automation dan } \\
\text { webmail } \\
\text { E-Surat }\end{array}$ \\
\hline
\end{tabular}

b. Pembentukan divisi SI/TI dan Penambahan Personil Untuk membantu menangani masalah dalam pengaksesan aplikasi, data dan berkaitan dengan teknologi untuk mebantu dalam pengelolaan data dan aplikasi serta berinteraksi langsung dengan pengguna, diperlukan sebuah divisi khusus SI/TI. Selain itu sebaiknya dilakukan penambahanan tiga pralatan komputer yang akan menangani masing masing bagian bidang pendidikan yang ada. Penambahan juga diperlukan untuk melakukan penyediaan data pendidikan, analisis dan pengembangan statistik, dan pengembangan profesi yang berdasarkan pada kebutuhan Lembaga.

c. Rancangan Portofolio Mendatang

Rancangan portofolio mendatang dilakukan dengan menggunakan matrik portofolio aplikasi McFarlan untuk mengetahui gambaran tentang kontribusi setiap aplikasi terhadap organisasi saat ini dan masa mendatang. Sebelum dipetakan ke dalam matrik McFarlan, terlebih dahulu dilakukan analisa berdasarkan tinggi atau rendahnya ketergantungan SI saat ini dan tinggi atau rendahnya kepentingan TI masa depan seperti yang dapat dilihat pada tabel 7. dejarat kepentingan SI/TI di bawah ini. 
Tabel 12. Derajat Kepentingan SI/TI

\begin{tabular}{|c|l|c|c|c|c|}
\hline \multirow{2}{*}{ No } & \multicolumn{2}{|c|}{ Solusi SI/TI } & \multicolumn{2}{|c|}{$\begin{array}{c}\text { Current } \\
\text { dependence on } \\
\text { IS }\end{array}$} & \multicolumn{2}{c|}{$\begin{array}{c}\text { Future } \\
\text { importance of IT }\end{array}$} \\
\hline 1 & High & Low & High & Low \\
\hline & $\begin{array}{l}\text { SI Pemetaan } \\
\text { Lembaga dan } \\
\text { aset } \\
\text { Lembaga }\end{array}$ & $\sqrt{ }$ & & & $\sqrt{ }$ \\
\hline 2 & $\begin{array}{l}\text { SI Peserta } \\
\text { didik dan } \\
\text { Akademik }\end{array}$ & $\sqrt{ }$ & & $\sqrt{ }$ & \\
\hline 3 & $\begin{array}{l}\text { SI Sumber } \\
\text { daya } \\
\text { Manusia }\end{array}$ & $\sqrt{ }$ & & $\sqrt{ }$ \\
\hline 4 & $\begin{array}{l}\text { Learning } \\
\text { management }\end{array}$ & $\sqrt{ }$ & & & \\
\hline
\end{tabular}

\begin{tabular}{|l|c|c|c|c|} 
McFarlan & \multicolumn{2}{|c|}{$\begin{array}{c}\text { Current } \\
\text { dependence on IS }\end{array}$} & \multicolumn{2}{c|}{$\begin{array}{c}\text { Futu Future } \\
\text { importance of IT }\end{array}$} \\
\hline Category & High & Low & High & Low \\
\hline Strategic & $\sqrt{ }$ & & $\sqrt{ }$ & \\
\hline $\begin{array}{l}\text { Key } \\
\text { Operational }\end{array}$ & $\sqrt{ }$ & & & $\sqrt{ }$ \\
\hline $\begin{array}{l}\text { High } \\
\text { Potential }\end{array}$ & & $\sqrt{ }$ & $\sqrt{ }$ & \\
\hline Support & & $\sqrt{ }$ & & $\sqrt{ }$ \\
\hline
\end{tabular}

Berdasarkan tabel derajat kepentingan SI/TI di atas selanjutnya dapat dikategorikan kemudian solusi SI/TI dimasukkan ke dalam tabel matrik McFarlan seperti yang dapat dilihat pada tabel 13. berikut.

Tabel 13. Kategori Portofolio SI/TI

\begin{tabular}{|l|c|c|c|c|}
\hline McFarlan & \multicolumn{2}{|c|}{$\begin{array}{c}\text { Current } \\
\text { dependence on IS }\end{array}$} & \multicolumn{2}{c|}{$\begin{array}{c}\text { Futu Future } \\
\text { importance of IT }\end{array}$} \\
\hline Category & High & Low & High & Low \\
\hline Strategic & $\sqrt{ }$ & & $\sqrt{ }$ & \\
\hline $\begin{array}{l}\text { Key } \\
\text { Operational }\end{array}$ & $\sqrt{ }$ & & & $\sqrt{ }$ \\
\hline $\begin{array}{l}\text { High } \\
\text { Potential }\end{array}$ & & $\sqrt{ }$ & $\sqrt{ }$ & \\
\hline Support & & $\sqrt{ }$ & & $\sqrt{ }$ \\
\hline
\end{tabular}

Hasil Rancangan portofolio mendatang yang dihasilkan sesuai kategori matrik McFarlan seperti pada tabel 14. berikut.

Tabel 14. Portofolio SI/TI LPK.Duta Prima Yang Akan Datang

\begin{tabular}{|l|l|}
\hline \multicolumn{1}{|c|}{ STRATEGIC } & \multicolumn{1}{c|}{ HIGH POTENTIAL } \\
\hline SI SDM PTK dan PPB & SI Pemetaan Lembaga \\
(Sumber daya manusia & dan Aset Sasaran Kerja \\
Pendidik dan Tenaga & Karyawan (dalam \\
Kependidikan \& & pengembangan) \\
Pengembangan & \\
\hline
\end{tabular}

\begin{tabular}{|l|l|}
\hline Profesi Berkelanjutan) & \\
\hline KEY OPERATIONAL & \multicolumn{1}{|c|}{ SUPPORT } \\
\hline $\begin{array}{l}\text { SI Peserta didik / Siswa } \\
\text { dan Akademik }\end{array}$ & SI Penerimaan Peserta \\
Didik / Baru \\
$\begin{array}{l}\text { Learning Management } \\
\text { RAPBS (Rencana } \\
\text { anggaran } \\
\text { pendapatan dan belanja } \\
\text { Lembaga ) }\end{array}$ & $\begin{array}{l}\text { Prabumulih Aplikasi } \\
\text { office automation dan } \\
\text { webmail } \\
\text { E-Surat }\end{array}$ \\
\hline
\end{tabular}

\section{Kesimpulan}

Berdasarkan hasil dan pembahasan yang telah dijelaskan diatas, dapat diambil kesimpulan sebagai berikut:

1. Hasil penelitian yang dilakukan adalah sebuah kerangka kerja perencanaan strategi SI/TI yang dapat digunakan pada sebuah Lembaga Pendidikan sesuai dengan tinjauan penelitian.

2. Perancangan strategi SI/TI pada LPK. Duta Prima prabumulih dilakukan dengan menggunakan metodologi Ward dan Peppard dengan Faktor-faktor penting dapat dilihat dari hasil analisa SWOT, PEST, Analisa Value Chain yang dapat dilakukan dengan melakukan rancangan portofolio masa yang akan datang yang digunakan untuk membantu proses Penanganan Peserta didik/ siswa pada kerja lembaga terhadap strategi dan model bisnis di Lpk. Duta Prima Prabumulih.

3. Hasil Rancangan Portofolio SI/TI mendatang berdasarkan pemetaan aplikasi matrik McFarlan yaitu pada kwadran strategicSumberdaya manusia Pendidik dan Tenaga Kependidikan LPK. Duta Prima dan Pengembangan profesional Berkelanjutan, pada kwadran key operational Sistem informasi data peserta didik/siswa dan Akademik serta learning management, Sistem Informasi Peserta Didik pada kwadran high potensial Pemetaan lembaga dan Aset lembaga.

\section{Saran}

Adapun saran didalam keberlanjutan penelitan untuk tema yang sama sebagai berikut:

1. Rencana strategis teknologi dan sistem informasi yang disusun dalam penelitian ini, dapat di tindak lanjuti dengan kegiatan dan pengadaan perkembangan teknologi dan sistem informasi dengan portofolio masa depan yang telah disusulkan.

2. Pada setiap tahap implementasi, sebaiknya setelah dilakukan pelatihan dilakukan evaluasi pelaksanaan implementasi. 
3. Kebijakan keamanan SI/TI yang akan dibangun sebaiknya selalu memenuhi kebutuhan dasar keamanan sistem informasi yaitu: kerahasiaan, kendali akses, otentikasi, integritas dan tidak menyangkal pengiriman dan penerimaan file pada sistim jaringan.

\section{Daftar Pustaka}

Bryson, John. 2007. Perencanaan Strategis bagi Organisasi Sosial: Pustaka Belajar Offset. Yogyakarta

Widyaningsih, Pipin. 2012 Perencanaan Strategis Sistem Informasi pada Institusi Pendidikan Tinggi menggunakan Analisis Critical Success Factors, Semarang, Universitas Diponegoro

Gates, L.P., 2010. Strategic Planning with Critical Success Factors and Future Scenarios: An Integrated Strategic Planning Framework, Carniege Mellon University. Http://www.sei.cmu.edu, diakses pada 8 Februari 2015

Handayaningrat, Soewarno. 1988. Administrasi Pemerintahan dalam Pembangunan Jakarta : Haji Mas Agung

Kadir, A. 2003 Pengenalan Sistem Informasi, Yogyakarta, ANDI.Ward, J. \& Peppard, J. 2002 Strategic Planning for Information System 3th, England, John Wiley and Sons.

Kotler, Philip \& Gary Amstrong. 1999. Prinsip-prinsip Pemasaran, Jilid I Edisi kelima. Jakarta: Erlangga.

Hariadi, B. 2003. Strategi manajemen, (cetakan pertama). Penerbit Bayu Media, Malang.

Mustakini, J. H. 2008. Metodologi Penelitian Sistem Informasi, Penerbit Andi Yogyakarta.

Rangkuti, F. 2004. Analisis SWOT Teknik Membedah Kasus Bisnis. PT. GramediaPustaka Utama, Jakarta

Anggelina. 2012. Perencanaan Strategis Sistem Informasi Pada Direktorat Jenderal Peternakan Dan Kesehatan Hewan, Kementerian Pertanian. Tesis. Universitas Bina Nusantara. Jakarta 